\title{
To study the laboratory profile of severe malaria in a tertiary care centre of North India
}

\author{
Sood $\mathbf{R}^{1}$, Rajamanickam $\mathbf{T}^{2}$, Singh $\mathbf{N}^{3}$ \\ ${ }^{1}$ Dr. Rahul Sood, Department of Nephrology, ${ }^{2}$ Dr.Timothy Rajamanickam, Department of Nephrology, ${ }^{3}$ Dr. Navjot \\ Singh, Department of Medicine; all authors are affiliated with Christian Medical College and Hospital, Ludhiana, Punjab, \\ India.
}

Address for Correspondence: Dr. Rahul Sood, Email: rahul_sood_23_sep@yahoo.co.in

\begin{abstract}
Introduction: Malaria ranks third among the major infectious diseases in causing deaths- after pneumococcal acute respiratory infections and tuberculosis. It is expected that by the turn of the century malaria would be the number one infectious killer disease in the world. It is the most widely distributed and is responsible for up to 400 million infections every year. The aim of the study was to describe the laboratory parameters and their correlation with mortality in Malaria. Methods: This was a one year retrospective and one and half year prospective study. All patients diagnosed to have Malaria were included in this study. Results: Laboratory parameters were recorded carefully and the data was analyzed by the appropriate statistical methods. A total of 124 patients were studied 92 patients of Plasmodium vivax, 21 patients of Plasmodium falciparum and 11 patients of Mixed malaria. Complications observed were severe anemia $(<7$ $\mathrm{gm} / \mathrm{dl}$ ), thrombocytopenia, renal dysfunction (S.creat $>1.2 \mathrm{mg} / \mathrm{dl}$ ), raised bilirubin $>3 \mathrm{mg} \%$, metabolic acidosis, and acute respiratory distress syndrome (ARDS). Thrombocytopenia and jaundice were the most frequent complications in the severe cases. 10/124 patients (8.06\%) expired. 8/10 patients who expired had four or more organ dysfunction. Conclusion: ARDS had the most significant correlation with mortality. Other significant factors contributing to death were jaundice, severe anemia and renal failure.
\end{abstract}

Key words: Laboratory parameters, mortality, outcome, severe malaria

\section{Introduction}

India contributes to about $70 \%$ of Malaria in the South East Asia region. Annually India reports about two million cases and 1,000 deaths attributable to Malaria [1]. There exists heterogeneity and variability in the transmission between and within the states of the country as many ecotypes / paradigms of Malaria have been recognized. Among the four species of Plasmodium, Plasmodium falciparum and vivax are commonly found in our country. Disease caused by Plasmodium vivax Malaria used to be called benign tertian. In contrast Plasmodium falciparum causes severe Malaria and often produces multi-organ failure unless treated early with multiple drugs. Recently there have been some isolated reports showing severe Plasmodium vivax Malaria associated with

Manuscript received $25^{\text {th }}$ August 2016

Reviewed: $7^{\text {th }}$ September 2016

Author Corrected: $18^{\text {th }}$ September 2016

Accepted for Publication $1^{\text {st }}$ October 2016 thrombocytopenia, cerebral malaria, acute respiratory distress syndrome, acute renal failure and hepatic dysfunction. Kochar et al in a study reported several cases of vivax Malaria with multi-organ dysfunction syndrome [2]. Profound thrombocytopenia is a wellrecognized complication of falciparum malaria but recently there have been several reports of vivax malaria with thrombocytopenia [3,4] Direct lytic effect, immunological reactions, splenic sequestration and oxidative stress are some of suggested mechanisms for thrombocytopenia [5,6]. Acute respiratory distress syndrome (ARDS), hepatic involvement and renal involvement are common in Plasmodium falciparum Malaria; these complications also have been reported in Plasmodium vivax Malaria [7-12]. Morbidity and mortality of Plasmodium vivax have increased recently due to the serious complications associated with it. There are very few prospective studies on laboratory 
profile of Malaria. Taking this background, we planned a study to document the association of laboratory parameters with changing clinical profile of this common disease.

\section{Materials and Methods}

This was a descriptive study, which was done in the Department of Medicine, Christian Medical College and Hospital, Ludhiana, over a period of two and half years (one and a half year prospective and one year retrospective study). In retrospective study, data was collected from case records of all cases admitted to Christian Medical College and Hospital, Ludhiana, with diagnosis of Malaria from 1st October 2008 to $30^{\text {th }}$ September, 2009. In prospective study (1st October 2009 to 31st March, 2011), all patients admitted and diagnosed as Malaria were included. Diagnosis of Malaria was made by examining the peripheral blood smear (thick and thin smear). Parasite index will be calculated in all cases. All cases enrolled in the study underwent OptiMAL malarial antigen test to rule out falciparum-vivax co-infection (mixed malaria). Opti MAL is a rapid (10 minutes) malaria detection test which utilizes a dipstick coated with monoclonal antibodies against the intracellular metabolic enzyme parasite lactate dehydrogenase. Differentiation of malaria parasite was based on antigenic difference between pLDH isoforms. OptiMAL has sensitivity of $95.3 \%$ and specificity of $100 \%$ for Plasmodium falciparum and sensitivity of $96 \%$ and specificity of $100 \%$ for Plasmodium vivax. Complete blood count, renal function test, liver function test, arterial blood gases analysis, chest $\mathrm{x}$-ray conducted. Imaging (CT scan, MRI) wherever required. Treatment was given to all patients as per WHO guidelines. Patient's clinical features, laboratory parameters and response to treatment were recorded as per data collection sheet. Patients were categorized into Plasmodium vivax, Malaria, Plasmodium falciparum Malaria and mixed infection. The study was approved by hospital ethics committee and the information obtained from this study were tabulated in a master chart and then analyzed to obtain measurable data. Percentages were calculated for a number of patients in different groups to convey appropriate statistical information.

Statistical Analysis- To compare mean values of a variable between more than two groups, we used analysis of variance [ANOVA] and to compare two proportions of subjects we applied Z-test.

\section{Results}

This was a descriptive study, done in the Department of Medicine, Christian Medical College and Hospital, Ludhiana. Study was done over a period of 21/2 years (one year retrospective from 1st October, 2008 to 30th September 2009 and one and half year prospective from 1st October, 2009 to 31st March, 2011). All patients admitted at Christian Medical College and Hospital, Ludhiana with a diagnosis of Malaria were included and following observations were made. A total of 124 patients were studied 92 patients of Plasmodium vivax, 21 patients of Plasmodium falciparum and 11 patients of mixed malaria [Table:1]. Male: Female ratio was $3.8: 1$. Pallor and jaundice were seen significantly more in Plasmodium falciparum and Mixed malaria. 49/124 patients had hemoglobin < 10gm/dl and 119/124 (95.92\%) had thrombocytopenia [Table:2]. Severe malaria was observed in 39/124 patients of which 25 (27.12\%) were of Plasmodium vivax, $9(42.86 \%)$ were of Plasmodium falciparum and $5(45.45 \%)$ were of Mixed malaria. Thrombocytopenia and jaundice were the most frequent complications in the severe cases. Mixed malaria was found in 11 cases. 5 of them were severe cases [Table: 3]. 54/92 of plasmodium vivax cases responded to chloroquine alone. 31 patients $(33.7 \%)$ required artesunate or combinations. 10/124 patients (8.06\%) expired. Out of these $4(4.38 \%)$ were of plasmodium vivax, 3 $(14.28 \%)$ were plasmodium falciparum and $3(27.27 \%)$ were mixed malaria. 8/10 patients who expired had four or more organ dysfunction. ARDS had the most significant correlation with mortality [Table:3]

Table-1: Distribution of subjects according to OPTIMAL and MP Smear test results.

\begin{tabular}{|c|c|c|c|c|}
\hline Results & OptiMAL test & Percentage & MP Smear Positive & Percentage \\
\hline PV positive & 92 & 74.19 & $74(88)$ & 62.7 \\
\hline PF positive & 21 & 16.94 & $10(19)$ & 8.47 \\
\hline Mixed malaria & 11 & 8.87 & $7(11)$ & 7.63 \\
\hline Total & 124 & 100.00 & $91(118)$ & 77.1 \\
\hline
\end{tabular}


Table-2: Laboratory Parameters.

\begin{tabular}{|c|c|c|c|c|c|c|c|}
\hline Parameter & \multicolumn{2}{|c|}{ PF positive } & \multicolumn{2}{|c|}{ PV positive } & \multicolumn{2}{|c|}{ Mixed malaria } & \multirow[t]{2}{*}{ p value } \\
\hline $\mathbf{H b}$ & No. & Percentage & No & Percentage & No. & Percentage & \\
\hline$>12 \mathrm{~g} \%$ & 6 & 28.57 & 27 & 29.35 & 0 & & \multirow{4}{*}{0.049} \\
\hline $10-12 \%$ & 6 & 28.57 & 32 & 34.78 & 4 & 36.36 & \\
\hline $7-10 \%$ & 5 & 23.81 & 27 & 29.35 & 7 & 63.63 & \\
\hline$<7 \%$ & 4 & 19.04 & 6 & 6.52 & 0 & 0 & \\
\hline Mean \pm SD & \multicolumn{2}{|c|}{$10.06 \pm 3.38$} & \multicolumn{2}{|c|}{$10.89 \pm 2.42$} & \multicolumn{2}{|c|}{$9.41 \pm 1.25$} & \\
\hline \multicolumn{8}{|l|}{ Leucocyte count } \\
\hline$<4000$ & 4 & 19.04 & 20 & 21.74 & 3 & 27.29 & \multirow{3}{*}{0.977} \\
\hline $4,000-11,000$ & 13 & 61.9 & 68 & 73.91 & 7 & 63.63 & \\
\hline$>11,000$ & 4 & 19.04 & 4 & 4.35 & 1 & 9.09 & \\
\hline Mean \pm SD & \multicolumn{2}{|c|}{$7319.04 \pm 4931.7$} & \multicolumn{2}{|c|}{$7014.13 \pm 7918.36$} & \multicolumn{2}{|c|}{$7254.55 \pm 4159.41$} & \\
\hline \multicolumn{8}{|l|}{ Platelet count } \\
\hline$>1,50,000$ & 1 & 4.76 & 4 & 4.35 & 0 & 0.00 & \multirow{5}{*}{0.196} \\
\hline $1,00,00-1,50,000$ & 3 & 14.29 & 11 & 11.96 & 1 & 9.09 & \\
\hline $50,000-1,00,000$ & 6 & 28.57 & 20 & 21.74 & 3 & 27.27 & \\
\hline $20,000-50,000$ & 8 & 38.09 & 39 & 42.39 & 5 & 45.45 & \\
\hline$<20,000$ & 3 & 14.29 & 18 & 19.56 & 2 & 18.18 & \\
\hline Mean \pm SD & \multicolumn{2}{|c|}{$42352.94 \pm 22433.07$} & \multicolumn{2}{|c|}{$37592.11 \pm 23545.8$} & \multicolumn{2}{|c|}{$38300 \pm 20155.23$} & \\
\hline
\end{tabular}

\begin{tabular}{|c|c|c|c|c|c|c|c|}
\hline Parameter & \multicolumn{2}{|c|}{ PF positive } & \multicolumn{2}{|c|}{ PV positive } & \multicolumn{2}{|c|}{ Mixed malaria } & \multirow[t]{2}{*}{ p value } \\
\hline Bilirubin & No. & Percentage & No & Percentage & No. & Percentage & \\
\hline$<1.1 \mathrm{mg} \%$ & $4(17)$ & 23.52 & $19(56)$ & 33.92 & $2(8)$ & 25.00 & \\
\hline $1.1-3.00 \mathrm{mg} \%$ & $7(17)$ & 41.17 & $23(56)$ & 41.07 & $2(8)$ & 25.00 & 0.17072 \\
\hline$>3.00 \mathrm{mg} \%$ & $7(17)$ & 41.17 & $14(56)$ & 25.00 & $4(8)$ & 50.00 & \\
\hline Mean \pm SD & \multicolumn{2}{|c|}{$5.02 \pm 6.79$} & \multicolumn{2}{|c|}{$3.17 \pm 4.28$} & \multicolumn{2}{|c|}{$3.89 \pm 3.48$} & \\
\hline \multicolumn{8}{|l|}{ SGOT( 10-40 U) } \\
\hline$<40 \mathrm{U}$ & 8 & 38.09 & $49(82)$ & 59.75 & $3(9)$ & 33.33 & \multirow{3}{*}{0.04891} \\
\hline $40-120 \mathrm{U}$ & 9 & 42.86 & $30(82)$ & 36.58 & $6(9)$ & 66.67 & \\
\hline$>120 \mathrm{U}$ & 4 & 19.04 & $03(82)$ & 3.66 & 0 & 0 & \\
\hline Mean \pm SD & \multicolumn{2}{|c|}{$86.43 \pm 99.15$} & \multicolumn{2}{|c|}{$51.89 \pm 42.26$} & \multicolumn{2}{|c|}{$81.00 \pm 90.03$} & \\
\hline \multicolumn{8}{|l|}{ SGPT(10-40 U) } \\
\hline$<40 \mathrm{U}$ & 8 & 38.09 & $53(82)$ & 64.63 & $6(9)$ & 66.67 & \multirow{3}{*}{0.03245} \\
\hline $40-120 \mathrm{U}$ & 10 & 47.62 & $24(82)$ & 29.27 & $3(9)$ & 33.33 & \\
\hline$>120 \mathrm{U}$ & 3 & 14.28 & $05(82)$ & 6.09 & 0 & 0 & \\
\hline Mean \pm SD & \multicolumn{2}{|c|}{$73.14 \pm 74.68$} & \multicolumn{2}{|c|}{$43.53 \pm 36.30$} & \multicolumn{2}{|c|}{$39.20 \pm 16.66$} & \\
\hline
\end{tabular}




\begin{tabular}{|c|c|c|c|c|c|c|c|}
\hline Parameter & \multicolumn{2}{|c|}{ PF positive } & \multicolumn{2}{|c|}{ PV positive } & \multicolumn{2}{|c|}{ Mixed malaria } & $p$ value \\
\hline BUN (10-45mg\%) & No. & Percentage & No & Percentage & No. & Percentage & \\
\hline$<45$ & 6 & 28.57 & $52(91)$ & 57.14 & 3 & 27.27 & \multirow{3}{*}{0.041} \\
\hline $45-100$ & 13 & 61.9 & $31(91)$ & 34.06 & 4 & 36.36 & \\
\hline$>100$ & 2 & 9.52 & $7(91)$ & 7.69 & 4 & 36.36 & \\
\hline Mean \pm SD & \multicolumn{2}{|c|}{$64.48 \pm 37.35$} & \multicolumn{2}{|c|}{$48.58 \pm 33.34$} & \multicolumn{2}{|c|}{$75.64 \pm 48.38$} & \\
\hline \multicolumn{8}{|l|}{$\operatorname{Crt}(0.3-1.1 \mathrm{mg} \%)$} \\
\hline$<1.2 \mathrm{mg} \%$ & 14 & 66.67 & 72 & 78.26 & 5 & 45.45 & \multirow{3}{*}{0.01697} \\
\hline $1.2-3.0$ & 6 & 28.57 & 17 & 18.48 & 6 & 54.54 & \\
\hline$>3.0$ & 1 & 4.76 & 3 & 3.36 & 0 & 0 & \\
\hline Mean \pm SD & \multicolumn{2}{|c|}{$1.46 \pm 1.11$} & \multicolumn{2}{|c|}{$1.08 \pm 1.01$} & \multicolumn{2}{|c|}{$1.20 \pm 0.58$} & \\
\hline
\end{tabular}

\begin{tabular}{|c|c|l|c|l|l|l|l|}
\hline ABG pO2 & & & & & & & \\
\hline$<60 \%$ & $1(10)^{*}$ & & $5(20)$ & & $1(5)$ & & \multirow{2}{*}{0.56743} \\
\hline $60-90 \%$ & $4(10)$ & & $11(20)$ & & $1(5)$ & & \\
\hline$>90 \%$ & $5(10)$ & & $4(20)$ & & $3(5)$ & & \\
\hline
\end{tabular}

Table-3 Frequency of various complications in severe malaria.

\begin{tabular}{|c|c|c|c|c|}
\hline Criteria & $\begin{array}{c}\text { P. vivax } \\
\text { No }(\%) \text { of patients } \\
25(27.1)\end{array}$ & $\begin{array}{c}\text { P. falciparum } \\
\text { No }(\%) \text { of patients } \\
\quad 9(\mathbf{4 2 . 8 6})\end{array}$ & $\begin{array}{c}\text { Mixed } \\
\text { No }(\%) \text { of patients } \\
5(45.45)\end{array}$ & $\begin{array}{c}\text { Total } \\
\text { No }(\%) \text { of patients } \\
39(\mathbf{3 1 . 4 5 )}\end{array}$ \\
\hline $\begin{array}{l}\text { Severe anemia } \\
\quad<7 \mathrm{mg} \%\end{array}$ & 5 & 4 & 2 & 11 \\
\hline Encephalopathy & 3 & 3 & 4 & 10 \\
\hline Hypotension & 10 & 2 & 3 & 15 \\
\hline Jaundice $>3 \mathrm{mg} \%$ & 16 & 7 & 4 & 27 \\
\hline $\begin{array}{l}\text { Creatinine } \\
>3 \mathrm{mg} \%\end{array}$ & 3 & 3 & 0 & 6 \\
\hline $\begin{array}{c}\text { Thrombocytopenia }< \\
80,000\end{array}$ & 23 & 9 & 5 & 37 \\
\hline ARDS & 7 & 4 & 2 & 13 \\
\hline Hypoglycemia & 1 & 0 & 0 & 1 \\
\hline Acidosis & 3 & 4 & 1 & 8 \\
\hline Expired & 4 & 3 & 3 & 10 \\
\hline Upto 2 organ failure & 15 & 2 & 1 & 18 \\
\hline $\begin{array}{c}3 \text { or more organ } \\
\text { failure }\end{array}$ & 10 & 7 & 4 & 21 \\
\hline
\end{tabular}

\section{Discussion}

In our study, laboratory findings in malaria caused by various plasmodium species were being described. The prevalence of different types of malaria varies in different regions and states of India. In our study majority of the patients belonged to the state of Punjab where Plasmodium vivax is the predominant type. [13]. Among clinical features fever was the leading presentation in our study. In our study, pallor, jaundice and hepatosplenomegaly were the most common signs observed. Jaundice was noticed in $42.8 \%$ of
Plasmodium falciparum and $36.3 \%$ of mixed malaria. In Plasmodium vivax only $22.83 \%$ of cases had jaundice. In a study done at Rohtak by Nityanand and Agarwal jaundice was described in $100 \%$ of the Plasmodium falciparum patients as compared to $42.8 \%$ in this study [14].

Laboratory Profile of Patients- Among hematological profile, thrombocytopenia is a common feature of acute malaria and occurs in both P. falciparum and P.vivax 
regardless of the severity of infection. Severe thrombocytopenia has been reported most commonly with P. falciparum [15]. In our study, 95.24\% of falciparum, $95.65 \%$ of vivax and $100 \%$ cases of mixed malaria had thrombocytopenia. This hematological alteration is a result of peripheral destruction and consumption. A few postulated mechanisms for thrombocytopenia in malaria include macrophage activation, increased levels of cytokines and antiplatelet immunoglobulin which cause platelet destruction. Other mechanisms include oxidative stress, sequestration in non-splenic areas and pseudothrombocytopenia due to clumping of platelets [16]. Another common hematological complication seen in malaria is Anemia. The two common causes of anemia are increased hemolysis and decreased rate of erythrocyte production from bone marrow [17]. Cytokine-related dyserythropoiesis also probably contributes to anem1ia [18]. Severe anemia is a common feature of $\mathrm{P}$. falciparum malaria. In vivaxendemic areas, P. vivax is a major risk factor for severe anemia, particularly in young children [19]. Malnutrition and intestinal parasitic infections aggravate this problem in highly endemic areas. In our study, $42.8 \%$ of falciparum, $35.8 \%$ vivax and $63.6 \%$ of mixed malaria had anemia $(\mathrm{Hb}<=10 \mathrm{mg} \%)$. In a study from Bikaner, anemia was reported in $54 \%$ of falciparum malaria [20]. In yet another study conducted in Indore, anemia was reported in $56.06 \%$ of Plasmodium falciparum and $31.8 \%$ Plasmodium vivax infection respectively [21].

Renal involvement has been reported commonly with P. falciparum and occasionally with P.vivax infections. It can occur as an isolated complication or as a component of multiorgan involvement [22]. The precise mechanism of ARF in malaria is not clearly known. Several hypotheses including mechanical obstruction caused by cytoadherence and sequestration of infected erythrocytes, immune-mediated glomerular pathology, alterations in the renal and systemic hemodynamics, release of cytokines, reactive oxygen intermediates, and nitric oxide have been proposed.

The hemolysis, disseminated intravascular coagulation, and rhabdomyolysis in malaria also contribute to the pathogenesis of ischemic tubular necrosis and ARF [23]. Various histological pictures including acute tubular necrosis (the commonest), interstitial nephritis, and proliferative glomerulonephritis have been described in malarial ARF either alone or in combination [22,24,25].
Glomerular injury associated with malaria is commonly seen in the pediatric population. Mild proteinuria, microhematuria, and casts are reported in $20 \%-50 \%$ of cases [26]. Both nephrotic and acute nephritic syndromes have been described with falciparum and vivax malaria $[27,28]$.

Renal impairment is known to occur with falciparum malaria but is rare in patients of vivax malaria. However there have been reports of ARF, electrolyte abnormality, abnormal proteinuria and urinary sediments in vivax malaria. In our study, $33.3 \%$ of Plasmodium falciparum, $54.5 \%$ of mixed malaria and $21.7 \%$ of Plasmodium vivax had renal dysfunction. In our study there were statistically more number of patients with renal dysfunction in plasmodium falciparum and mixed malaria. In a study from Rajasthan in falciparum malaria $21.7 \%$ of patients had uremia [29]. In another study from Bikaner on severe plasmodium vivax malaria $45 \%$ had renal dysfunction [30]

Hepatic dysfunction in malaria is common, but hepatic encephalopathy is unusual, and most of the patients described have had either isolated infection with P.falciparum or a mixed infection with P.vivax [31]. In endemic areas, severe malaria should feature in the differential diagnosis of fulminant hepatic failure (FHF). In this study 26 patients had hyperbilirubinemia (Total Bilirubin >3 gm\%). Hyperbilirubinemia observed in cases of vivax malaria can be attributed to increased hemolysis of both parasitized and non-parasitized erythrocytes as well as to hepatic injury, as has been observed in cases with P. falciparum malaria [32]. Similar to falciparum malaria, dilated hepatic sinusoids containing hypertrophied kupffer cells and parasitized red cells may also be contributory to hepatic injury in Plasmodium vivax infection [33]

Alterations in pulmonary physiology in malaria include airflow obstruction, impaired ventilation, reduced gas transfer, and increased pulmonary phagocytic activity [34]. Acute respiratory distress syndrome (ARDS) in malaria is likely to be a continuous spectrum from subclinical lung involvement in uncomplicated malaria to frank ARDS in severe malaria [35]. ARDS is considered to be the most severe form of acute lung injury in malaria and has been reported most commonly with P. falciparum malaria. The prevalence of ARDS in patients with malaria as documented in various studies ranges from $2.1 \%$ to $29.1 \%$ [36]. 
Pulmonary edema has been reported by several investigators to be one of the fatal complications of P. falciparum malaria often in association with disseminated intravascular coagulation, renal failure, cerebral malaria, and shock. Fein et al emphasized that pulmonary edema in patients with $\mathrm{P}$. falciparum malaria is noncardiogenic resulting from increased permeability of the alveolar-capillary membrane [37].

In this study, cough was present in 24/124 (19.4\%) of the patients, while $14 / 124(11.3 \%)$ of the patients had breathing difficulty. ARDS/ALI was present in 13 cases, of which 7 were Plasmodium vivax and 4 cases were of Plasmodium falciparum, 2 were cases of mixed malaria. Six patients required mechanical ventilation. There are only a few well-documented reports of ARDS in Plasmodium vivax infected cases. Tanios et al; 2001, had reported a case of Plasmodium vivax complicated by ARDS [38]. In a study from Rajasthan, 11 cases of severe vivax malaria were reported 3 of which had ARDS [2].

Complications in severe malaria are either sequestration related, such as cerebral malaria, renal dysfunction, hepatic dysfunction, and ARDS, or non-sequestration related, such as anemia and thrombocytopenia. Nonsequestration-related complications are known to occur in Plasmodium vivax infection quite frequently. However, for sequestration-related complications, it was always presumed that coexisting Plasmodium falciparum infection may evade appearance in blood film because of heavy sequestration.

Previously, it was thought that the severe disease with vivax infection is actually caused by co-infection of vivax and falciparum species.However, with application of the recently developed tests of malarial antigen it has become evident that vivax mono-infection can be a cause of severe malaria. The mechanisms of organ involvement in vivax malaria are controversial. In this study $39(31.45 \%)$ patients had severe malaria, diagnosed as per WHO criteria. The most common complication observed was thrombocytopenia. The other complications observed were jaundice and hepatic dysfunction, which is similar to the reported observations in severe Plasmodium falciparum malaria and Plasmodium vivax malaria in this region [2,7,8,30]. For predicting the outcome of severe falciparum malaria scoring system have been devised [39]. This scoring system have taken into consideration various organ dysfunction for the prediction of the outcome.
Mohapatra and Das have suggested another scoring system called MSS (Malaria Severity Score) [40]. Here 7 organ dysfunction were taken into consideration namely Neurologic, Renal, hematological, cardiovascular, respiratory, hepatic and metabolic dysfunction.

General awareness of the presentations of complicated malaria such as hepatic dysfunction jaundice and renal failure is needed among primary care physicians so as to treat these patients in more appropriate way. Routinely, jaundiced patients with altered consciousness and a short history are considered to have viral hepatitis rather than malarial hepatitis. This can sometimes leads to disaster in terms of prompt institution of appropriate therapy. There was a significant association of ARF with rising bilirubin levels. This elevation of bilirubin was typically an increase in conjugated bilirubin. The concomitant renal failure may contribute to the elevated conjugated hyperbilirubinemia by virtue of decreased excretion of conjugated bilirubin. Once the complications develop removal of parasites could not reverse the organ damage and hence the mortality. Therefore, in addition to antimalarial drugs, organ support is mandatory in the management of severe malaria.

Although P. vivax malaria is widely considered benign, recent studies have demonstrated that it accounts for a substantial proportion of hospitalized malaria patients in agreement with our study. The observation that a significant proportion of severe malaria morbidity is also caused by $\mathrm{P}$. vivax would have tremendous implications for control of the infection especially as P. vivax invariably increases relative to $P$. falciparum under effective transmission reduction [41,42]. Thus, every effort to reduce or eliminate malaria burden must also target $\mathrm{P}$. vivax along with $\mathrm{P}$. falciparum in regions where both of these species coexist.

\section{Conclusions}

Plasmodium vivax malaria was the commonest type of malaria observed. Severe plasmodium vivax was associated with all the complications described in falciparum malaria. Mixed malaria was associated with the largest proportion of severe malaria and the mortality was the highest in this group. Laboratory parameters play a very vital role in predicting the outcome for these patients. ARDS had the most significant correlation with mortality. Other significant factors contributing to death were jaundice, severe 
anemia and renal failure. Age and platelet counts had no significant correlation to mortality. Patients of malaria should be monitored for occurrence of different complications as their early detection and the appropriate treatment or referral to higher center can be life-saving.

\section{Funding: Nil, Conflict of interest: None. Permission of IRB: Yes}

\section{Bibilography}

1. Dash AP, Valecha N, Anvikar AR, Kumar A. Malaria in India: challenges and opportunities. J Biosci. 2008 Nov;33(4):583-92.

2. Kochar DK, Saxena V, Singh N, Kochar SK, Kumar SV, Das A. Plasmodium vivax malaria. Emerg Infect Dis. 2005 Jan;11(1):132-4.

3. Makkar RP, Mukhopadhyay S, Monga A, Monga A, Gupta AK. Plasmodium vivax malaria presenting with severe thrombocytopenia. Braz J Infect Dis. 2002 Oct; $6(5): 263-5$

4.Rodríguez-Morales AJ, Sánchez E, Vargas M, Piccolo C, Colina R, Arria M, Franco-Paredes C. Occurrence of thrombocytopenia in Plasmodium vivax malaria. Clin Infect Dis. 2005 Jul 1;41(1):130-1. DOI: 10.1086/ 430837.

5. Fajardo L.F, Tallent C. Malarial parasites within human platelets. JAMA,1974; 229:1205-9

6. Yamaguchi S, Kubota T, Yamagishi T, Okamoto K, Izumi $\mathrm{T}$, et al. Severe thrombocytopenia suggesting immunological mechanisms in two cases of vivax malaria. Am J Hematol. 1997 Nov;56(3):183-6.

7. Nautiyal A, Singh S, Parameswar G, Disalle M. Hepatic dysfunction in a patient of $\mathrm{P}$. vivax Malaria. Med Gen Med. 2005; 7(1): 8. PMCID: PMC1681376

8. Kochar DK, Singh P, Agarwal P, Kochar SK, Pokharna R, Sareen PK. Malarial hepatitis. J Assoc Physicians India. 2003 Nov;51:1069-72.

9. Anand AC, Ramji C, Narula AS, Singh W. Malarial hepatitis: a heterogeneous syndrome?. Natl Med J India. 1992 Mar-Apr;5(2):59-62.

10. Prakash J, Singh AK, Kumar NS, Saxena RK. Acute renal failure in Plasmodium vivax malaria. J Assoc Physicians India. 2003 Mar;51:265-7.
11. Maheshwari A, Singh AK, Sinha DK, Tripathi K, Prakash J.Spectrum of renal disease in malaria. J Indian Med Assoc. 2004 Mar;102(3):143, 146, 148 passim

12. Lomar AV, Vidal JE, Lomar FP, Barbas CV, de Matos GJ, Boulos M. Acute respiratory distress syndrome due to vivax malaria: case report and literature review. Braz J Infect Dis. 2005 Oct;9(5):42530. Epub 2006 Jan 6.

13. Kumar A, Valecha N, Jain T, Dash AP. Burden of malaria in India: retrospective and prospective view. Am J Trop Med Hyg. 2007 Dec;77(6 Suppl):69-78

14. Nityanand, Agarwal HK. Hepatic and renal dysfunction. JAPI 1997; 45:

15. Agarwal A, Rath S, Shashiraj, 2005. Plasmodium vivax malaria presenting with severe thrombocytopenia. J Trop Pediatr. 2005 Apr ;51(2): 120-1.

16. Katira B, Shah I. Thrombocytopenia in Plasmodium vivax infected children. J Vector Borne Dis. 2006; 43(3):147-49.

17. Weatherall DJ. The anaemia of malaria. In: McGregor I, ed. Wernsdorfer WH, eds. Malaria: Principles and Practice of Malariology. New York: Churchill Livingstone 1988; pp 735-51

18. Anstey NM, Russell B, Yeo TW, Price RN. The pathophysiology of vivax malaria. Trends Parasitol. 2009;25(5):220-27.

19.Haldar K, Mohandas N. Malaria, erythrocytic infection, and anemia. Hematology Am Soc Hematol Educ Program. 2009:87-93

20. Gupta A, Mathotra HS, Bombary P, Mittal PC, Sharma SK. Clinical pattem of complicated malaria in North West India. JAPI 1987;

21. Jain, M.A. and Kaur, M.B.: Comparative study of microscopic detection methods with hematological changes in malaria. Ind J PatholMicrobiol., 2005; 48(4):464-7.

22. Das BS. Renal failure in malaria. J Vector Borne Dis. 2008;45(2): 83-97.

23. Prakash J, Singh AK, Gujrati S, Maheshwari A. Acute renal failure in malaria: changing trends. Indian $\mathbf{J}$ Nephrol. 2002;12(4):113-17. 
24. Barsoum RS. Malarial acute renal failure. J Am Soc Nephrol. 2000; 11(11):2147-54

25. Barsoum RS. Malarial nephropathies. Nephrol Dial Transplant . 1998; 13(6):1588-97

26. Boonpucknavig V, Sitprija V. Renal disease in acute P. Falciparum. Kidney Int. 1979; 16: 44-52

27. David J, Shanbag P, More V. Plasmodium vivax malaria presenting as the nephrotic syndrome in an infant. Trop Doct. 2009 Apr;39(2):127-8. doi: 10. 1258/td.2008.080288.

28. Sanghai SR, Shah I. Plasmodium vivax with acute glomerulonephritis in an 8-year old. J Vector Borne Dis. 2010;47(1):65-6.

29. Bajiya HN, Kochar DK. Incidence and outcome of neurological sequelae in survivors of cerebral malaria. JAPI 1996; 44(10): 679- 81.

30. Kochar DK, Das A, Kochar SK, Saxena V, Sirohi P, Garg S, Kochar A, Khatri MP, Gupta V. Severe Plasmodium vivax malaria: a report on serial cases from Bikaner in northwestern India. Am J Trop Med Hyg. 2009 Feb;80(2):194-8

31. Bhalla A, Suri V, Singh V. Malarial hepatopathy. J Postgrad Med. 2006;52(4):315-20.

32. Wilairatana $\mathrm{P}$, Looareesuwan S, Vanijanonta S, Charoenlarp P, Wittayalertpanya S. Hepatic metabolism in severe falciparum malaria: caffeine clearance study. Ann Trop Med Parasitol. 1994 Feb;88(1):13-9.

33. Mishra SK, S. Mohanty, B.S. Das, J.K. Patnail, S.K. Satpathy, D. Mohanty and T.K. Bose, Hepatic changes in P falciparum malaria, Indian J. Malariol. 29 (1992), pp. 167-71

34. Anstey NM, Jacups SP, Cain T, et al. Pulmonary manifestations of uncomplicated falciparum and vivax malaria: cough, small airways obstruction, impaired gas transfer, and increased pulmonary phagocytic activity. J Infect Dis. 2002;185(9):1326-34.

35. Maguire GP, Handojo T, Pain MC, Kenangalem E, Price RN, Tjitra E, Anstey NM. Lung injury in uncomplicated and severe falciparum malaria: a longitudinal study in papua, Indonesia. J Infect Dis. 2005 Dec 1;192(11):1966-74. Epub 2005 Nov 1.

36. Mohan A, Sharma SK, Bollineni S. Acute lung injury and acute respiratory distress syndrome in malaria. J Vector Borne Dis. 2008;45(3):179-93.

37. Fein IA, Rackow EC, Shapiro L. Acute pulmonary edema in Plasmodium falciparum malaria. Am Rev Respir Dis. 1978;118(2):425-29.

38. Tanios MA, Kogelman L, McGovern B, Hassoun $P M$, 2001. Acute respiratory distress syndrome complicating Plasmodium vivax malaria. Crit Care Med 29: 665-67

39. Mishra SK, Panigrahi P, Mishra R, Mohanty S. Prediction of outcome in adults with severe falciparum malaria: a new scoring system. Malar J. 2007 Feb 27;6:24.

40. Tanios MA, Kogelman L, McGovern B, Hassoun PM. Acute respiratory distress syndrome complicating Plasmodium vivax malaria. Crit Care Med. 2001 Mar;29(3):665-7.

41. Mendis K, Sina BJ, Marchesini P, Carter R. The neglected burden of Plasmodium vivax malaria. Am J Trop Med Hyg. 2001 Jan-Feb;64(1-2 Suppl):97-106.

42. Rogerson SJ, Carter R. Severe vivax malaria: newly recognised or rediscovered. PLoS Med. 2008 Jun 17;5(6):e136. doi: 10.1371/journal.pmed.0050136.

\section{How to cite this article?}

Sood R, Rajamanickam T, Singh N.To study the laboratory profile of severe malaria in a tertiary care centre of North India. Int J Med Res Rev 2016;4(10):1907-1914.doi:10.17511/ijmrr. 2016.110.30. 